\title{
BMJ Open Objective assessment of clinical, oncological and cosmetic outcomes following volume replacement in patients undergoing oncoplastic breast- conserving surgery: protocol for a systematic review
}

\author{
Jesse Hu, ${ }^{1}$ Richard M Rainsbury, ${ }^{2}$ Ashvina Segaran, ${ }^{1}$ Oana Predescu, ${ }^{1}$ \\ Pankaj G Roy ${ }^{1}$
}

To cite: Hu J, Rainsbury RM, Segaran A, et al. Objective assessment of clinical, oncological and cosmetic outcomes following volume replacement in patients undergoing oncoplastic breastconserving surgery: protocol for a systematic review. BMJ Open 2018;8:e020859. doi:10.1136/ bmjopen-2017-020859

Received 30 November 2017 Revised 9 May 2018 Accepted 5 June 2018
Check for updates

(c) Author(s) (or their employer(s)) 2018. Re-use permitted under CC BY-NC. No commercial re-use. See rights and permissions. Published by BMJ.

${ }^{1}$ Department of Breast Surgery, Oxford University Hospitals NHS Trust, Oxford, UK

${ }^{2}$ Department of Breast Surgery, Hampshire Hospitals NHS

Foundation Trust, Winchester, UK

Correspondence to

Jesse Hu;

jesse_hu@nuhs.edu.sg

\section{ABSTRACT}

Introduction Oncoplastic breast surgery allows the excision of larger tumours without compromising cosmetic outcome and can be broadly divided into volume displacement and volume replacement techniques. Although oncoplastic surgery has rapidly gained acceptance and is now widely practised, evidence is still lacking especially in patients who underwent volume replacement techniques. As it is a relatively new technique that has been described in the literature in the recent years, a summary of evidence from this literature can help clinicians to understand the clinical, oncologicalandcosmetic outcomes of such procedures.

Methods and analysis All original studies including randomised controlled trials, cohort studies, casecontrol studies and case series involving more than 10 women undergoing partial breast reconstruction using a volume replacement technique will be included. The primary objective is to evaluate the clinical, oncological and cosmetic outcomes following volume replacement in patients undergoing oncoplastic breast-conserving surgery. The secondary objective is to review the patient-reported outcomes (PROMs) associated with oncoplastic breast surgery to help identify any unmet needs and to consider refining the existing PROMs to suit women undergoing volume replacement surgery. A comprehensive literature search, eligibility assessment and extraction of data will be conducted by two trained teams acting independently. Data will be extracted and stored in a database with standardised extraction fields to facilitate easy and consistent data entry. Heterogeneity will be assessed using the Cochrane tests.

Ethics and dissemination This systematic review requires no ethical approval. It will be published in a peer-reviewed journal, and it will also be presented at nationalandinternational conferences.

PROSPERO registration number CRD42017075700; Pre-results.
Strengths and limitations of this study

This will be the first review to specifically focus on volume replacement techniques.

- The search for studies is limited by English language.

- Many of the publications of new techniques are reporting small numbers of patients and hence potential lack of high-quality studies limiting the ability to conduct a meta-analysis.

- It would be difficult to tease out volume displacement and volume replacement techniques.

- Potential reporting bias within the existing literature.

\section{INTRODUCTION}

Surgery for breast cancer has evolved dramatically over the years, from Halsted's radical mastectomy that was standard of care for all women diagnosed with breast cancer right up to the 1960 s, to the development and acceptance of breast-conserving therapy as standard of care in more recent years. Breast-conserving therapy refers to breast-conserving surgery (BCS) followed by radiotherapy. BCS has been found to have equivalent diseasefree and overall survival when compared with mastectomy and hence has become the standard of care for early-stage breast cancer.

The primary aim of BCS is tumour excision to achieve tumour-free resection margins while the secondary aim is to achieve a satisfactory cosmetic outcome. Although many early cancers can be successfully treated by standard lumpectomy, some lesions still remain a challenge for breast surgeons to achieve a good outcome especially with regards to patients with large tumour:breast size ratio. Oncoplastic breast surgery ${ }^{1-4}$ combines oncological resection with plastic 
surgery techniques and allows the excision of larger tumours without compromising cosmetic outcome.

Oncoplastic breast surgery can be broadly divided into two fundamentally different techniques: (1) volume displacement using glandular or dermoglandular redistribution of breast tissue into the resection site; (2) volume replacement using autologous tissues from an extra mammary site to compensate for volume loss after tumour resection. Women with small breasts or a large tumour:breast ratio may not be suitable for volume displacement and hence volume replacement serves as an alternative to mastectomy. Examples of volume replacement techniques include the latissimus dorsi miniflap, chest wall perforator flaps, omental flaps and so on.

Although oncoplastic surgery has rapidly gained acceptance and is now widely practised, evidence is still lacking on both short-term and long-term outcomes, especially in patients following volume replacement. As with any relatively new technique, a summary of evidence from the literature can help clinicians to understand the clinical, oncological and cosmetic outcomes of these novel procedures.

\section{What have we learnt from prior systematic reviews?}

Previous systematic reviews have largely focused on oncoplastic breast surgery as a collective group (see table 1). Volume replacement techniques have been developing and gaining acceptance, and we feel there is a need to focus on these techniques as a separate entity, analysing the latest publications. A summary of published evidence will update the clinical, oncological and cosmetic outcomes of these procedures. Our study proposes to look specifically at the clinical, oncological and aesthetic outcomes patients undergoing volume replacement alongside oncoplastic BCS.

\section{Why is it important to do this systematic review?}

As volume replacement techniques have been developing and gaining acceptance, there is a need to focus on it as a separate entity and to include the latest available literature.

Since the most recent systematic review of oncoplastic breast surgery concluded its search in 2015, there have been over 30 more articles published in regards to partial breast reconstruction using volume replacement technique. A new systematic review is needed to update our understanding of this rapidly evolving area of clinical practice and to address the questions unanswered by previous studies.

\section{OBJECTIVES}

The primary objective of this review is to evaluate the clinical, oncological and cosmetic outcomes following volume replacement in patients undergoing oncoplastic BCS.

A secondary objective is to review the patient-reported outcomes (PROMs) associated with oncoplastic breast surgery to help identify any unmet needs and to consider refining the existing PROMs to suit women undergoing volume replacement surgery.

\section{METHODS AND ANALYSIS}

This review will be conducted in line with the recommendations specified in the Cochrane Handbook for intervention reviews V.5.1.0. It will be reported in line with the Preferred Reporting Items for Systematic Reviews and Meta-analyses statement.

\section{Inclusion and exclusion criteria}

To minimise heterogeneity and to address the objectives of the review, studies will be selected according to the criteria outlined below.

\section{Study designs}

We will include all randomised controlled trials (RCTs), cohort and case-control studies. Single group cohorts and case series will be included if there are more than 10 patients who underwent volume replacement after oncoplastic BCS. Hence, levels of evidence 1-4 as defined by the Oxford Centre for Evidence-Based Medicine. ${ }^{5}$ Case reports, abstracts, expert opinions and duplicate studies will be excluded. Only studies published in English will be included.

\section{Participants}

Only women with breast cancer who are undergoing partial breast reconstruction using volume replacement in BCS will be included. Men, patients who underwent mastectomy and patients who underwent surgery for benign breast conditions will be excluded.

\section{Interventions}

Partial breast reconstruction using volume replacement such as chest wall perforator flaps, latissimus dorsi miniflaps and other volume replacement techniques. Volume displacement techniques such as therapeutic mammoplasty and usage of non-autologous tissue will be excluded.

\section{Outcomes}

The primary objective of this review is to evaluate the clinical, oncological and cosmetic outcomes following volume replacement in patients undergoing oncoplastic BCS. Early clinical outcomes include clinical complications such as flap necrosis, infection, re-admission, re-excision and completion mastectomy rates. Later clinical outcomes include correction of symmetry (contralateral augmentaion/reduction), nipple reconstruction, correction of deformity (lipomodelling, scar revision etc), mastectomy for recurrence and any other procedures. Oncological outcomes include overall survival and local recurrence rate in the follow-up period. Cosmetic outcomes include cosmetic results and cosmetic evaluation method.

A secondary objective is to review the PROMs associated with oncoplastic breast surgery to help identify 
Table 1 Prior reviews of volume replacement in patients undergoing oncoplastic breast-conserving surgery

\begin{tabular}{lll}
\hline Review & $\begin{array}{l}\text { Databases included and } \\
\text { years searched }\end{array}$ & Studies included \\
\hline Losken et al $2014^{5}$ & PubMed & 61 papers \\
& \\
& \\
& & \\
Haloua et al $2013^{7}$ & $\begin{array}{l}\text { MEDLINE, EMBASE and } \\
\text { Cochrane 2000-2011 }\end{array}$ & $\begin{array}{l}12 \text { studies - most are volume } \\
\text { displacement techniques }\end{array}$
\end{tabular}

\section{Key findings}

Meta-analysis comparing breast conservation therapy and oncoplastic breast surgery. Length of follow-up in the oncoplastic breast surgery group was shorter than breast conservation therapy. Main focus was on age, tumour size and local recurrence. Very little focus on the various techniques available and cosmetic outcomes

This systematic review reveals that current evidence supporting the efficacy of oncoplastic breast surgery is based on poorly designed and underpowered studies. Given the increasing importance and application of oncoplastic breast surgery, there is a pressing need for robust comparative studies, including both randomised controlled trials and well-designed, multicentre prospective longitudinal studies

\begin{tabular}{|c|c|c|c|}
\hline $\begin{array}{l}\text { Yiannakopoulou and Mathelin } \\
2016^{8}\end{array}$ & $\begin{array}{l}\text { PubMed, Scopus, } \\
\text { Google Scholar, Science } \\
\text { citation Index 1966-2013 }\end{array}$ & $\begin{array}{l}40 \text { studies - only } 15 \text { were } \\
\text { volume replacement }\end{array}$ & $\begin{array}{l}\text { Study quality was low. The } \\
\text { majority of studies were } \\
\text { observational studies. The } \\
\text { length of follow-up was } \\
\text { relatively short; long-term } \\
\text { oncological outcome of } \\
\text { oncoplastic surgery for breast } \\
\text { cancer is not adequately } \\
\text { investigated. Further research } \\
\text { efforts should focus on Level } \\
\text { I evidence on oncological } \\
\text { outcome of oncoplastic } \\
\text { surgery }\end{array}$ \\
\hline De La Cruz et al $2016^{9}$ & PubMed 1988-2015 & $\begin{array}{l}55 \text { studies with broad } \\
\text { spectrum of oncoplastic } \\
\text { techniques }\end{array}$ & $\begin{array}{l}\text { Systematic review comparing } \\
\text { breast-conserving surgery } \\
\text { using oncoplastic techniques } \\
\text { in place of standard } \\
\text { lumpectomy. The review only } \\
\text { included T1 and T2 breast } \\
\text { cancers. The oncoplastic } \\
\text { techniques evaluated were } \\
\text { mainly volume displacement } \\
\text { (>50\%) but very little details or } \\
\text { surgical technique available }\end{array}$ \\
\hline $\begin{array}{l}\text { Yoon et al } \\
2016^{10}\end{array}$ & PubMed 1995-2015 & $\begin{array}{l}41 \text { studies - only } 11 \text { were } \\
\text { volume replacement }\end{array}$ & $\begin{array}{l}\text { Review comparing } \\
\text { postradiation outcomes of } \\
\text { volume replacement and } \\
\text { volume displacement. Did } \\
\text { not describe the surgical } \\
\text { techniques involved }\end{array}$ \\
\hline
\end{tabular}


any unmet needs and to consider refining the existing PROMs to suit women undergoing volume replacement surgery. PROMs include patient satisfaction and quality of life. We would also be looking at parameters, if reported in the published studies, optimising patient selection for these surgical procedures such as age, smoking history, comorbidity such as diabetes mellitus, tumour size and location, and preoperative breast/bra size.

\section{Search strategy}

The following electronic databases will be searched from January 1990 to 31 December 2017: MEDLINE, EMBASE, and the Cochrane database and Database of Abstracts of Reviews of Effect. This will be supplemented by a manual search of references lists and the review of 'epub ahead of print' articles.

A comprehensive search will be performed using the following search terms: breast conserving surgery, oncoplastic breast surgery, oncoplastic breast conserving surgery, partial breast reconstruction, partial mastectomy, immediate reconstruction and volume replacement. Additional keywords such as chest wall perforator flaps, latissimus dorsi mini flap, omental flap and further logical combinations of these and related terms will be used to maximise sensitivity. The search will include all study designs but limited to articles published in English.

Studies identified will be listed within a Microsoft Excel database and duplicates excluded. The selection of articles will be conducted by two teams who will independently evaluate the titles and abstracts to assess the eligibility in terms of outcome measures and study designs. The authors will be blinded to each other's results during the review process and the findings will then be compared. Discrepancies will be resolved through discussion. The full text of the articles selected will be further assessed for inclusion by two review authors. Where required, authors will be contacted to clarify inclusion, data overlap and data.

Once the study has been included, data extraction will be performed independently by two teams of researchers. Discrepancies will then be resolved by consensus.

Data will be extracted into a standardised Microsoft Excel database. The following data will be extracted:

- Author names, countries and year of publication.

- Study design and level of evidence.

- Conflicts of interest and funding.

- Number of participants.

- Number of breasts treated.

- Age of participants.

- Smoking history.

- History of diabetes.

- Preoperative breast/bra size.

- Oncological parameters-type of cancer (invasive or in situ), grade, stage, axillary nodal status, hormone receptor status (ER, PR), HER2 status, size of tumour including any associated additional foci, location of tumour (which quadrant), tumour-nipple distance, solitary or multifocal or multicentric and presence of lymphovascular invasion.

- Adjuvant radiotherapy.

- Prior neoadjuvant or adjuvant chemotherapy.

- Previous breast surgery.

- Technical details-incision used and reconstruction performed, whether flap included a skin paddle used to reconstruct a skin defect.

- Median follow-up duration.

- Loss to follow-up expressed as a percentage.

- Primary outcomes as described above.

- Early clinical outcomes including clinical complications such as flap necrosis, infection, re-admission, re-excision and completion mastectomy rates.

- Later clinical outcomes including correction of symmetry (contralateral augmentation/reduction), nipple reconstruction, correction of deformity (lipomodelling, scar revision etc), mastectomy for recurrence and any other procedures.

- Oncological outcomes include overall survival and local recurrence rate in the follow-up period.

- Cosmetic outcomes include cosmetic results, cosmetic evaluation method, patient's satisfaction and quality of life.

\section{Assessment of risk of bias}

We will use the Cochrane Risk of Bias Tool ${ }^{6}$ for RCTs and the ROBINS-1 tool for non-randomised studies. We will compare study protocols with final papers where possible and key missing information across all study types will be presented.

\section{Strategy for data synthesis and statistical analysis}

Outcomes of interest will be presented appropriately. We will provide a narrative synthesis of the findings from the included studies, structured around the type of intervention, target population characteristics, type of outcome and intervention content. We will provide summaries of intervention effects for each study by calculating risk ratios (for dichotomous outcomes) or standardised mean differences (for continuous outcomes).

We anticipate that there will be limited scope for meta-analysis because of the range of different outcomes measured across the small number of existing trials. We are not planning to perform any subgroup analysis.

\section{Patient and public involvement}

No patients or members of the public were involved in this manuscript.

Contributors RMR and PGR conceptualised the idea. JH and PGR drafted the manuscript. JH, RMR, AS, OP and PGR contributed to the development of the selection criteria, the risk of bias assessment strategy and data extraction criteria. JH, RMR, AS, OP and PGR read, provided feedback and approved the final manuscript.

Funding This research received no specific grant from any funding agency in the public, commercial or not-for-profit sectors.

Competing interests None declared.

Patient consent Not required. 
Provenance and peer review Not commissioned; externally peer reviewed.

Open access This is an open access article distributed in accordance with the Creative Commons Attribution Non Commercial (CC BY-NC 4.0) license, which permits others to distribute, remix, adapt, build upon this work non-commercially, and license their derivative works on different terms, provided the original work is properly cited, appropriate credit is given, any changes made indicated, and the use is non-commercial. See: http://creativecommons.org/licenses/by-nc/4.0/.

\section{REFERENCES}

1. Clough KB, Lewis JS, Couturaud B, et al. Oncoplastic techniques allow extensive resections for breast-conserving therapy of breast carcinomas. Ann Surg 2003;237:26-34.

2. Rainsbury RM. Surgery insight: Oncoplastic breast-conserving reconstruction-indications, benefits, choices and outcomes. Nat Clin Pract Oncol 2007;4:657-64.

3. Almasad JK. Breast reconstruction in conserving breast cancer surgery. Saudi Med J 2008;29:1548-53
4. Regaño S, Hernanz F, Ortega E, et al. Oncoplastic techniques extend breast-conserving surgery to patients with neoadjuvant chemotherapy response unfit for conventional techniques. World $\mathrm{J}$ Surg 2009;33:2082-6.

5. Losken A, Dugal CS, Styblo TM, et al. A meta-analysis comparing breast conservation therapy alone to the oncoplastic technique. Ann Plast Surg 2014;72:145-9.

6. Higgins JP, Altman DG, Gøtzsche PC, et al. The Cochrane Collaboration's tool for assessing risk of bias in randomised trials. BMJ 2011;343:d5928.

7. Haloua MH, Krekel NM, Winters HA, et al. A systematic review of oncoplastic breast-conserving surgery: current weaknesses and future prospects. Ann Surg 2013;257:609-20.

8. Yiannakopoulou EC, Mathelin C. Oncoplastic breast conserving surgery and oncological outcome: systematic review. Eur J Surg Oncol 2016;42:625-30.

9. De La Cruz L, Blankenship SA, Chatterjee A, et al. Outcomes after oncoplastic breast-conserving surgery in breast cancer patients: a systematic literature review. Ann Surg Oncol 2016;23:3247-58.

10. Yoon JJ, Green WR, Kim S, et al. Oncoplastic breast surgery in the setting of breast-conserving therapy: a systematic review. Adv Radiat Oncol 2016;1:205-15 